\title{
Quality of normal delivery care in Côte d'Ivoire
}

\author{
Delvaux Thérèse $e^{1}$ Aké-Tano Odile ${ }^{2}$ Gohou-Konassi Valérie ${ }^{2}$ Bosso Patrice ${ }^{2}$ Collin Simon ${ }^{3}$ Ronsmans Carine ${ }^{3}$
}

\begin{abstract}
The aim of this study was to assess the quality of normal delivery care in Côte d'Ivoire. A total of 229 women were included in a cross-sectional study conducted in four urban maternity wards between 2002 and 2003. Observation checklists and exit-interviews were used to examine various dimensions of care. The results showed that the overall quality of care was poor, despite most women giving birth with a professional midwife. A vaginal examination was performed systematically at admission but blood pressure was measured in less than half of the women. The partograph was completed during labour in only $5 \%$ of cases. Episiotomy and uterine revision rates were high at $24 \%$ and $32 \%$, respectively. There was a lack of universal hygiene precautions and women received little support during labour. Our results question the quality of labour, delivery and postpartum care by skilled attendants in Côte d'Ivoire. (Rev Afr Santé Reprod 2007; 11[1]:22-32)
\end{abstract}

\section{RÉSUMÉ}

Qualité du service de l'accouchement normal en Côte-d'Ivoire Cette étude avait pour but d'évaluer la qualité du service de l'accouchement normal en Côte-d'Ivoire. Au total, 229 femmes ont fait partie de cette étude transversale qui a été menée dans quatre salles d'accouchement urbaines entre 2002 et 2003. On s'est servi des listes de contrôle de l'observation et les interviews de sortie pour examiner des dimensions différentes du service. Les résultats ont montré que dans l'ensemble la qualité du service est médiocre, malgré le fait que la plupart des femmes accouchent avec l'assistance d'une sage-femme professionnelle. On a effectué systématiquement un examen vaginal au moment de l'admission mais nous n'avons mesuré la pression artérielle que chez moins d'une moitié des femmes. La partagraphe n'a été complétée pendant le travail que chez 5\% des cas. Et les taux de l'épisiotomie et de la révision de l'utérin étaient élevés, s'élevant jusqu'à $24 \%$ et $32 \%$, respecitvement. On a remarqué un manque de précautions d'hygiène universelle et les femmes n'ont reçu que très peu de soutien pendant le travail. Nos résultats mettent en question la qualité des services du travail et du soin du post-partum par les auxillaires habiletés en Côte d'Ivoire. (Rev Afr Santé Reprod 2007; 11[1]:22-32)

KEY WORDS: Skilled attendance, basic obstetric care, quality of care

${ }^{1}$ Institute of Tropical Medicine, Antwerp, Belgium ${ }^{2}$ Institute National de Santé Publique, Côte d'Ivoire ${ }^{3}$ London School of Hygiene and Tropical Medicine, London, UK

Correspondence: Reprint request: T. Delvaux, STD/HIV Research and Intervention Unit, Department of Microbiology, Institute of Tropical Medicine, 155 Nationalestraat, B-2000 Antwerp, Belgium. Fax 32.3.247.6532, email tdelvaux@itg.be 


\section{Introduction}

Essential obstetric care is a major component of safe motherhood and includes basic and comprehensive obstetric care. 'The term 'basic' obstetric care should not undervalue the complexity and the skills required to attend normal delivery that can suddenly become an emergency. ${ }^{2}$ Immediate and effective professional care at and after childbirth can make the difference between life and death for both women and their newborns, as complications are largely unpredictable. ${ }^{2-6}$ For this reason skilled attendance at birth is being promoted as the most important strategy to reduce maternal and neonatal mortality, and the proportion of deliveries attended by skilled providers is used as a key measure of progress towards the fifth Millennium Development Goal of improving maternal health. ${ }^{7}$

A skilled attendant has been defined as a medically qualified provider with midwifery skills (midwife, nurse or doctor) who has been trained to proficiency in the skills necessary to manage normal deliveries and to diagnose, manage or refer obstetric complications. ${ }^{3,6}$ A number of tasks have been identified as constituting skilled care $^{4}$ and an increasing number of studies are now looking into the performance of so-called skilled attendants. ${ }^{8-20}$ Measuring performance is difficult however, indicators of skilled delivery care have not been standardised, and some studies rely on record review only. ${ }^{17-20}$ The objective of this study was to assess quality of normal delivery care at first and secondary level health facilities in Côte d'Ivoire, using an observation checklist to measure adherence to internationally accepted criteria of obstetric care. This study was conducted before the implementation of prevention of mother-to-child transmission of HIV activities in those health facilities.

\section{Methods}

Study sites

This study was conducted in Abidjan, the capital of Côte d'Ivoire, and in San Pedro, a large harbour city $300 \mathrm{~km}$ West of Abidjan. Data were collected in the delivery wards of the Regional Hospital of San Pedro (CHR San Pedro), a health centre in San Pedro (Maternité Bardot) and two health centres in Abidjan: the "Formation de Santé Communautaire Urbaine Jean Delafosse" (FSU JDelafosse) and the "Centre de Santé Communautaire Urbain de Koumassi Grand Campement" (CSU Koumassi). The three health centres perform normal deliveries; CHR San Pedro, as a secondary referral hospital, also manages complicated deliveries. All facilities are publicly funded, performing between 1400 and 3000 deliveries per year.

\section{Quality of care assessment}

We documented the technical aspects of normal delivery care as well as supportive care and hygiene practices. We used observation checklists and exitinterviews, adapting instruments from a previous study in Abidjan. ${ }^{8}$ The observation checklists were developed using best practice guidelines from Côte d'Ivoire and elsewhere ${ }^{21-23}$ covering the following dimensions: examination at admission; diagnosis and monitoring during labour and delivery, newborn and post-partum care; interpersonal relationship and universal hygiene precautions. Day and hour of admission and delivery were also noted. Semi-structured patient questionnaires included questions on sociodemographic characteristics, advice and health information received, and satisfaction with care.

\section{Data collection}

Data collection took place between July 2002 and May 2003. We observed deliveries in all four delivery wards, and interviewed women in the post-partum ward. Observations and exit interviews were done on the same women by a pair of medical doctors who were not practicing at the study sites, and who were specially trained in study methods. They were posted in each delivery ward, one to observe deliveries, and the other to interview women after delivery. Fifty 
normal deliveries were targeted in each health facility. Observations and interviews schedules were designed to obtain a representative sample of deliveries from all shifts, on normal week days as well as at night or during weekends. Among those time periods, all consecutive deliveries were included in the study.

\section{Ethical issues}

The study protocol was approved by the 'Comité d'éthique du Programme National de Lutte contre le VIH/SIDA (PNLS)' in Côte d'Ivoire and by the Ethics Committee of the London School of Hygiene and Tropical Medicine before data collection began. Observation and interview of women were conducted after provider and client verbal informed consents.

\section{Data analysis}

Data were analysed using Stata (StataCorp. 2003. Stata Statistical Software: Release 8. Texas, USA). Indicators of quality of delivery care were compared between facilities and by time-todelivery intervals using the Chi-squared test. Timeto-delivery intervals were non-normally distributed; Kruskal-Wallis one-way analysis of variance was used to compare median time-todelivery intervals between groups.

\section{Results}

\section{General characteristics of women}

We observed between 55 and 60 normal vaginal deliveries in each facility, making a total of 229 deliveries. An additional 6 deliveries by caesarean section were excluded from our analysis. The median age of the women was 24 years (range 15-48 years) and the median number of pregnancies was 2 (range 1-10). The majority of women had never been to school $(40 \%)$ or had only completed primary school (33\%); most were married (84\%). Nearly all women $(99 \%)$ had received at least one antenatal care visit and 53\% had completed three visits or more.

\section{Labour, delivery, post-partum and newborn care}

Table 1 presents data on technical aspects of delivery care. The majority of women were attended by a professional midwife, except in CSU Koumassi, where more than a third of women were attended by an "aide de santé" who has minimal nursing and no midwifery training. Six deliveries were conducted by a "fille de salle", a member of staff responsible for cleaning the delivery ward.

Women were generally seen within 2 minutes of admission, but the assessment of their general condition at admission was poor. Blood pressure was measured in less than half of the women (41\%); temperature and pulse were rarely checked (8\% and 3\% respectively) and only one woman was tested for presence of albumin in her urine (Table 1). The antenatal card was examined for most women, but history taking was brief and incomplete: only a quarter of women $(26 \%)$ were asked about the onset of labour pains, and a third (33\%) were asked whether the membranes had ruptured. A vaginal exam was performed in almost all women, and uterine height measured in $65 \%$, but the assessment of the foetal heart rate $(60 \%)$ or foetal position $(53 \%)$ was far from universal. Contractions were rarely monitored $(9 \%)$ and the partograph was seldom completed during labour $(5 \%)$. In two of the sites, the partograph was completed after delivery in more than $60 \%$ of deliveries.

Episiotomy rates were high (24\%), peaking at $60 \%$ at FSU Jean Delafosse. A positive finding regarding quality of care was that active management of the third stage of labour and oxytocics administration was a common practice, although paradoxically lower at the referral maternity (54\%). However, the placenta was almost never checked and uterine revision was done in a third of cases $(32 \%)$.

Post-partum care of the woman was generally conducted by the midwife, except in CSU Koumassi where $70 \%$ was carried out by an "aide de santé". Uterine retraction was checked in less

African Journal of Reproductive Health Vol. 11 No.1 April 2007 
Table 1: Technical aspects of normal delivery care in four health facilities in San Pedro and Abidjan, Côte d'Ivoire

\begin{tabular}{|c|c|c|c|c|c|c|}
\hline & $\begin{array}{l}\text { CHR San } \\
\text { Pedro } \\
(\mathrm{N}=54)\end{array}$ & $\begin{array}{l}\text { Maternité } \\
\text { Bardot } \\
(\mathrm{N}=60)\end{array}$ & $\begin{array}{l}\text { FSU Jean } \\
\text { Delafosse } \\
(\mathrm{N}=55)\end{array}$ & $\begin{array}{l}\text { CSU } \\
\text { Koumassi } \\
(\mathrm{N}=60)\end{array}$ & $\begin{array}{l}\text { Total } \\
(\mathrm{N}=229)\end{array}$ & P-value \\
\hline \multicolumn{7}{|l|}{ Attendance at delivery } \\
\hline Doctor & $0 \%$ & $0 \%$ & $0 \%$ & $8 \%$ & $2 \%$ & $<0.001$ \\
\hline Midwife & $96 \%$ & $97 \%$ & $100 \%$ & $56 \%$ & $86 \%$ & \\
\hline Other & $4 \%$ & $3 \%$ & $0 \%$ & $36 \%$ & $12 \%$ & \\
\hline \multicolumn{7}{|l|}{ Evaluation of general condition at first exam } \\
\hline Blood pressure & $20 \%$ & $47 \%$ & $84 \%$ & $15 \%$ & $41 \%$ & $<0.001$ \\
\hline Pulse & $0 \%$ & $0 \%$ & $9 \%$ & $3 \%$ & $3 \%$ & 0.010 \\
\hline Conjunctiva & $28 \%$ & $52 \%$ & $64 \%$ & $45 \%$ & $47 \%$ & 0.002 \\
\hline Check albumin in urine & $0 \%$ & $0 \%$ & $2 \%$ & $0 \%$ & $0 \%$ & 0.476 \\
\hline \multicolumn{7}{|c|}{ Diagnosis and monitoring of labour at first exam } \\
\hline Check antenatal card & $93 \%$ & $90 \%$ & $89 \%$ & $78 \%$ & $87 \%$ & 0.099 \\
\hline Asked about onset of labour pains & $34 \%$ & $22 \%$ & $40 \%$ & $13 \%$ & $27 \%$ & 0.005 \\
\hline Asked if membranes had ruptured & $33 \%$ & $30 \%$ & $51 \%$ & $18 \%$ & $33 \%$ & 0.003 \\
\hline Determine uterine height & $48 \%$ & $77 \%$ & $71 \%$ & $63 \%$ & $65 \%$ & 0.010 \\
\hline Determine position of fetus & $20 \%$ & $53 \%$ & $76 \%$ & $62 \%$ & $53 \%$ & $<0.001$ \\
\hline Measure fetal heart rate & $30 \%$ & $73 \%$ & $71 \%$ & $65 \%$ & $60 \%$ & $<0.001$ \\
\hline Vaginal examination & $93 \%$ & $95 \%$ & $98 \%$ & $98 \%$ & $96 \%$ & 0.337 \\
\hline Time contractions & $2 \%$ & $12 \%$ & $24 \%$ & $2 \%$ & $9 \%$ & $<0.001$ \\
\hline \multicolumn{7}{|l|}{ Monitoring of labour- Record keeping } \\
\hline Partograph filled during labour & $8 \%$ & $7 \%$ & $4 \%$ & $2 \%$ & $5 \%$ & $<0.001$ \\
\hline Partograph filled after delivery & $60 \%$ & $23 \%$ & $95 \%$ & $17 \%$ & $48 \%$ & \\
\hline Partograph not filled & $33 \%$ & $70 \%$ & $2 \%$ & $81 \%$ & $48 \%$ & \\
\hline \multicolumn{7}{|l|}{ Delivery and third stage of labour } \\
\hline Episiotomy: all women & $11 \%$ & $20 \%$ & $12 \%$ & $55 \%$ & $60 \%$ & $<0.001$ \\
\hline primiparous women & $96 \%$ & $17 \%$ & $50 \%$ & $24 \%$ & $64 \%$ & $<0.001$ \\
\hline Administrate oxytocics after delivery & $54 \%$ & $87 \%$ & $88 \%$ & $100 \%$ & $83 \%$ & $<0.001$ \\
\hline Examine placenta & $2 \%$ & $0 \%$ & $6 \%$ & $8 \%$ & $4 \%$ & 0.064 \\
\hline Uterine revision & $31 \%$ & $20 \%$ & $17 \%$ & $58 \%$ & $32 \%$ & $<0.001$ \\
\hline \multicolumn{7}{|l|}{ Post-partum care } \\
\hline Check uterine retraction & $37 \%$ & $43 \%$ & $27 \%$ & $12 \%$ & $28 \%$ & 0.003 \\
\hline Check blood pressure at least once & $11 \%$ & $67 \%$ & $51 \%$ & $7 \%$ & $34 \%$ & $<0.001$ \\
\hline \multicolumn{7}{|l|}{ Newborn care } \\
\hline Clear nose and mouth & $20 \%$ & $16 \%$ & $39 \%$ & $36 \%$ & $28 \%$ & 0.012 \\
\hline Apply antimicrobial ointment to eyes & $0 \%$ & $0 \%$ & $0 \%$ & $81 \%$ & $21 \%$ & $<0.001$ \\
\hline Disinfect cord & $88 \%$ & $100 \%$ & $65 \%$ & $79 \%$ & $83 \%$ & $<0.001$ \\
\hline Cover baby & $98 \%$ & $90 \%$ & $100 \%$ & $100 \%$ & $97 \%$ & 0.004 \\
\hline Put baby to breast immediately & $12 \%$ & $15 \%$ & $2 \%$ & $0 \%$ & $7 \%$ & 0.005 \\
\hline
\end{tabular}

than a third of cases. Blood pressure was measured once after delivery in 50-70\% of cases in Maternité Bardot and FSU Jean Delafosse, rarely at the secondary maternity in San Pedro $(11 \%)$ and the CSU Koumassi $(7 \%)$ in Abidjan. The newborn's nose and mouth were cleared in a third of cases and usually with a rubber pear rather than with proper aspiration. Antimicrobial ointment was applied in the eyes in one facility only. Proper cord care was not systematically done but the baby was generally dried, and covered. Breastfeeding was rarely initiated at the maternity ward.

\section{Hygiene practices}

Midwives almost never washed their hands before examination or delivery (Table 2). The perineum was almost never cleaned before vaginal exami- 
Table 2: Hygiene, supportive care and satisfaction with care among women with a normal delivery in four health facilities in San Pedro and Abidjan, Côte d'Ivoire

\begin{tabular}{|c|c|c|c|c|c|c|}
\hline & $\begin{array}{l}\text { CHR San } \\
\text { Pedro } \\
(\mathrm{N}=54)\end{array}$ & $\begin{array}{l}\text { Maternité } \\
\text { Bardot } \\
(\mathrm{N}=60)\end{array}$ & $\begin{array}{l}\text { FSU Jean } \\
\text { Delafosse } \\
(\mathrm{N}=55)\end{array}$ & $\begin{array}{l}\text { CSU } \\
\text { Koumassi } \\
(\mathrm{N}=60)\end{array}$ & $\begin{array}{l}\text { Overall } \\
(\mathrm{N}=229)\end{array}$ & P-value \\
\hline Wash hands before examination & $0 \%$ & $12 \%$ & $5 \%$ & $0 \%$ & $4 \%$ & 0.002 \\
\hline Wash perineum before examination & $4 \%$ & $0 \%$ & $0 \%$ & $3 \%$ & $2 \%$ & 0.262 \\
\hline Wash hands before delivery & $6 \%$ & $8 \%$ & $2 \%$ & $2 \%$ & $4 \%$ & 0.265 \\
\hline Box of sterile instruments for each delivery & $83 \%$ & $0 \%$ & $95 \%$ & $56 \%$ & $57 \%$ & $<0.001$ \\
\hline Instruments soaked in decontamination solution & $87 \%$ & $100 \%$ & $96 \%$ & $97 \%$ & $95 \%$ & 0.007 \\
\hline Skin disinfected before injection & $53 \%$ & $98 \%$ & $98 \%$ & $93 \%$ & $87 \%$ & $<0.001$ \\
\hline \multicolumn{7}{|l|}{ Interpersonal relationship } \\
\hline Someone is present to provide support & $19 \%$ & $15 \%$ & $30 \%$ & $15 \%$ & $19 \%$ & 0.148 \\
\hline Delivery is not seen by other patients & $22 \%$ & $68 \%$ & $91 \%$ & $78 \%$ & $65 \%$ & $<0.001$ \\
\hline Baby is shown to the mother & $11 \%$ & $32 \%$ & $2 \%$ & $10 \%$ & $14 \%$ & $<0.001$ \\
\hline \multicolumn{7}{|l|}{ Women's satisfaction with care } \\
\hline Was treated well/ very well & $87 \%$ & $93 \%$ & $84 \%$ & $83 \%$ & $87 \%$ & 0.338 \\
\hline $\begin{array}{l}\text { Would advice a friend to go to the same } \\
\text { maternity for delivery }\end{array}$ & $98 \%$ & $100 \%$ & $96 \%$ & $96 \%$ & $98 \%$ & 0.534 \\
\hline
\end{tabular}

nation or delivery although it was usually washed after delivery (not disinfected). A different glove was used for each vaginal examination and sterile gloves were always used for the delivery. Instruments for delivery were sterilized in all health facilities except for Maternité Bardot where the autoclave was out of order and instruments were disinfected with chlorine on a routine basis. Instruments were generally soaked in a decontamination solution after use.

\section{Interpersonal relationship and women's satisfaction about care}

Women received very little supportive care (Table 2). They were generally told how to lie down on the delivery table but few women were helped to climb up on to it. Little or no information was given about progress of labour, and in only $15-30 \%$ of cases did someone come at some point to support the woman, mostly maternity staff, seldom family members. During the intrapartum phase, women were moderately exposed to other patients $(35 \%)$, although this varied between facilities. Most women were satisfied with the care received.

\section{Time-to-delivery interval}

The time between admission and delivery was recorded for 226 women. The median time-todelivery interval was $1 \mathrm{hr} 20$ minutes (range, $1 \mathrm{~min}$ to 15 hours) with small variation between facilities $(p=0.05)$ (Figure 1). Women experiencing their first labour took a longer time to delivery (median $2 \mathrm{hrs} 05 \mathrm{mins}$ ) than multiparous women (median $1 \mathrm{hr} 17 \mathrm{mins}$ ) ( $\mathrm{p}=0.01$ ) (Figure 2). Table 3 presents some parameters monitored by the time from admission to delivery. Most women did not have their blood pressure taken, even those who stayed for 2 hours or more. The foetal position, uterine height and foetal heart rate, were measured somewhat more frequently among women who were in labour longer, but very few women had more than one measurement. Dilation was recorded for 110 women and data show, as 
Table 3: Monitoring of the condition of the mother and the foetus by time to delivery in four health facilities in San Pedro and Abidjan, Côte d'Ivoire

\begin{tabular}{|c|c|c|c|c|c|}
\hline & $\begin{array}{r}\text { Tir } \\
<1 \text { hour } \\
(\mathrm{N}=92)\end{array}$ & $\begin{array}{r}\text { between admis } \\
\begin{array}{r}1-<2 \text { hours } \\
(N=51)\end{array}\end{array}$ & $\begin{array}{r}\text { and deliver } \\
\text { - } 2 \text { hours } \\
(\mathrm{N}=88)\end{array}$ & $\begin{array}{r}\text { All } \\
(\mathrm{N}=226)\end{array}$ & $P$-value \\
\hline $\begin{array}{l}\text { Blood pressure taken } \\
\text { - never } \\
\text { - once } \\
\text { - more than once }\end{array}$ & $\begin{array}{r}60(65 \%) \\
32(35 \%) \\
0(0 \%)\end{array}$ & $\begin{array}{r}24(47 \%) \\
26(51 \%) \\
1(2 \%)\end{array}$ & $\begin{array}{r}49(59 \%) \\
30(36 \%) \\
4(5 \%)\end{array}$ & $\begin{array}{r}133(59 \%) \\
88(39 \%) \\
5(2 \%)\end{array}$ & 0.058 \\
\hline $\begin{array}{l}\text { Foetal heart rate measured } \\
\text { - never } \\
1(1 \%) \\
\text { - once } \\
\text { - more than once }\end{array}$ & $\begin{array}{r}49(53 \%) \\
42(46 \%) \\
0(0 \%)\end{array}$ & $\begin{array}{r}15(29 \%) \\
36(71 \%) \\
1(1 \%)\end{array}$ & $\begin{array}{r}26(32 \%) \\
55(67 \%) \\
2(1 \%)\end{array}$ & $\begin{array}{r}90(40 \%) \\
133(59 \%)\end{array}$ & 0.006 \\
\hline $\begin{array}{l}\text { Examines the position of the foetus } \\
\text { Check uterine height } \\
\text { Contractions timed } \\
\text { Contractions timed } \\
\text { - never } \\
\text { - once } \\
\text { - more than once }\end{array}$ & $\begin{array}{r}40(43 \%) \\
51(55 \%) \\
84(91 \%) \\
84(91 \%) \\
8(9 \%) \\
0(0 \%)\end{array}$ & $\begin{array}{r}32(63 \%) \\
36(71 \%) \\
47(92 \%) \\
47(92 \%) \\
4(8 \%) \\
0(0 \%)\end{array}$ & $\begin{array}{r}48(58 \%) \\
60(72 \%) \\
74(89 \%) \\
74(89 \%) \\
9(11 \%) \\
0(0 \%)\end{array}$ & $\begin{array}{r}120(53 \%) \\
147(65 \%) \\
205(91 \%) \\
205(91 \%) \\
21(9 \%) \\
0(0 \%)\end{array}$ & $\begin{array}{l}0.048 \\
0.042 \\
0.916 \\
0.916\end{array}$ \\
\hline $\begin{array}{l}\text { Vaginal examination } \\
\text { - never } \\
\text { - once } \\
\text { - more than once }\end{array}$ & $\begin{array}{r}4(4 \%) \\
75(82 \%) \\
13(14 \%)\end{array}$ & $\begin{array}{r}2(4 \%) \\
27(53 \%) \\
22(43 \%)\end{array}$ & $\begin{array}{r}2(2 \%) \\
42(48 \%) \\
44(50 \%)\end{array}$ & $\begin{array}{r}8(3 \%) \\
144(62 \%) \\
79(34 \%)\end{array}$ & $<0.001$ \\
\hline $\begin{array}{l}\text { Dilatation } \\
0-3 \mathrm{~cm} \\
4-8 \mathrm{~cm} \\
9-10 \mathrm{~cm} \\
\text { Oxytocics administered during labour }\end{array}$ & $\begin{array}{l}\mathrm{N}=42 \\
12(29 \%) \\
17(40 \%) \\
13(31 \%) \\
15(16 \%)\end{array}$ & $\begin{array}{r}N=26 \\
14(54 \%) \\
11(42 \%) \\
1(4 \%) \\
8(16 \%)\end{array}$ & $\begin{array}{r}\mathrm{N}=39 \\
33(85 \%) \\
5(13 \%) \\
1(3 \%) \\
18(22 \%)\end{array}$ & $\begin{array}{l}N=107 \\
59(55 \%) \\
33(31 \%) \\
15(14 \%) \\
41(18 \%)\end{array}$ & $<0.001$ \\
\hline
\end{tabular}

expected, that dilatation status was significantly related to time spent before delivery. Oxytocics were administrated to $18 \%$ of women during the first or second stage of labour (mostly by intramuscular injection), and was not related to time to delivery.

\section{Discussion}

This study shows that the technical standards of care for normal delivery were poor in all four facilities, whether for intrapartum, postpartum or newborn care. Vital signs or labour progress were not routinely monitored (if measured at all), the partograph was rarely filled in during labour, postpartum care for the mother or baby was poor and babies were seldom put at the breast after birth. Episiotomies, augmentation of labour with oxytocics and uterine revisions, on the other hand, were relatively common, suggesting that over-medicalisation also represents an element of substandard care.

Our findings are consistent with those from other studies in African countries and the Dominican Republic, Jamaica and Ecuador. ${ }^{8-15,17,18}$ Studies have consistently shown a lack of systematic monitoring of maternal or foetal signs during labour or progress of labour, ${ }^{8,10-13,15,17}$ low or incorrect use of the partograph, ${ }^{13,15,17-20}$ and poor postpartum care for both mother and baby. ${ }^{8,11,12,15}$ The low technical performance in terms of monitoring of labour is perhaps not surprising given the extremely short length of stay of the women in the delivery ward. The median time between admission and delivery was less than one and a half hours for all women, and only two hours for primiparous women. While such a short 


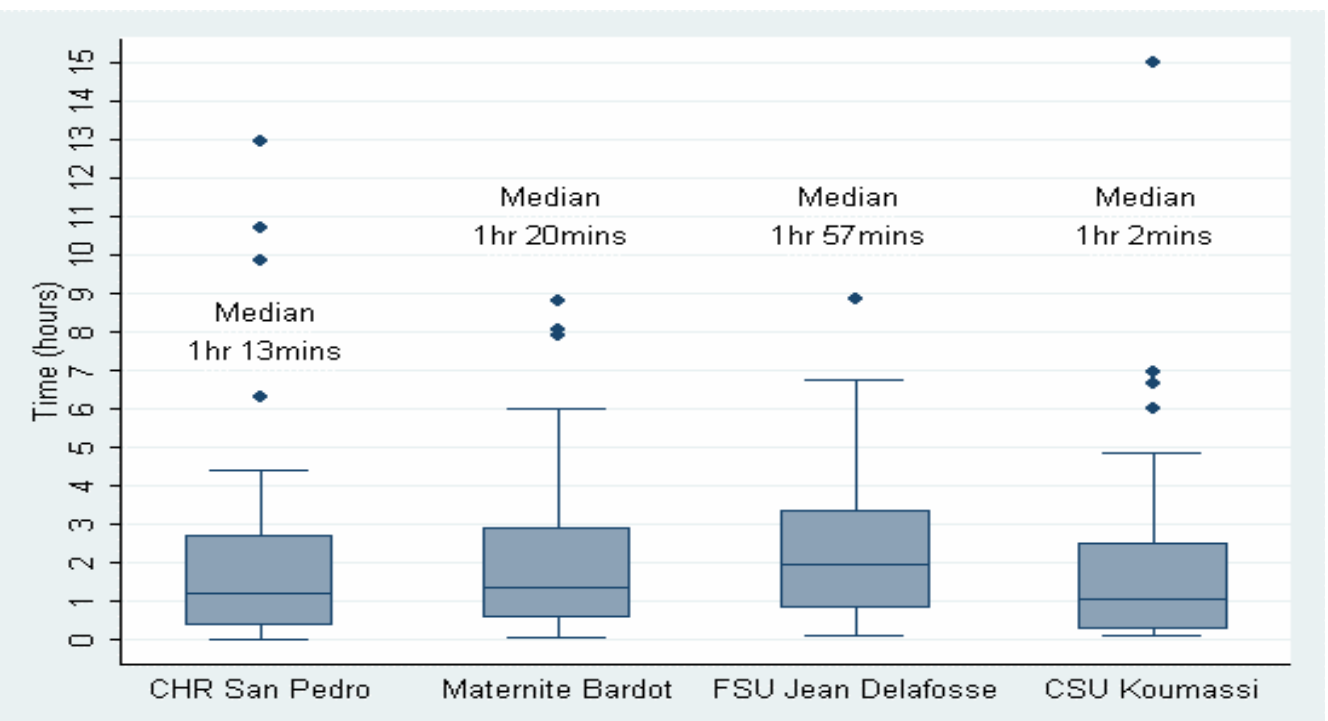

\section{Figure 1: Time-to-delivery by facility}

Median 'time-to-delivery interval differs by facility (Kruskal-Wallis test, $\mathrm{P}=0.05$ ). box shows median and interquartile range (IQR); whiskers indicate values 1.5xIQR above Q75 and below Q25

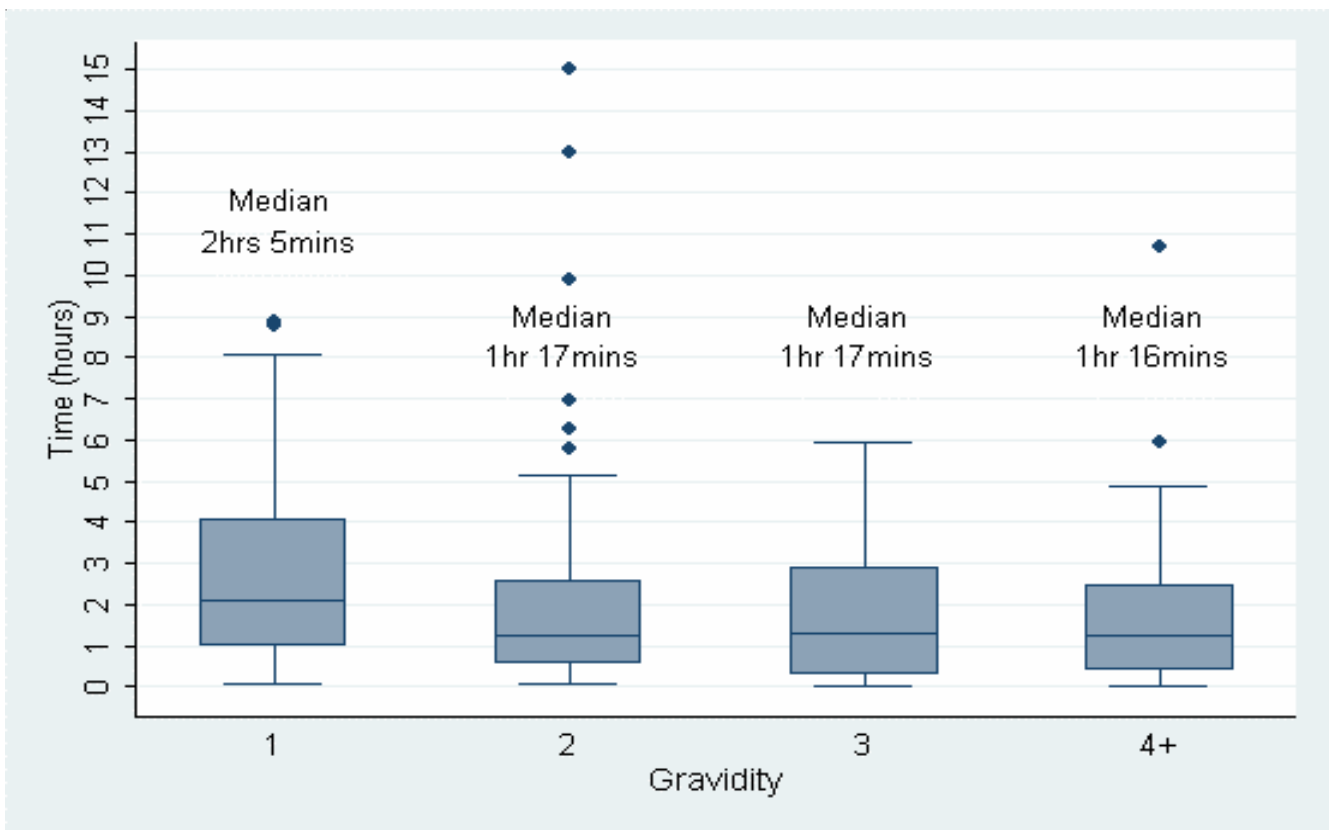

\section{Figure 2: Time-to-delivery by gravidity}

Median 'time-to-delivery interval differs by gravidity (Kruskal-Wallis test, $\mathrm{P}=0.01$ ). Box shows median and interquartile range (IQR); whiskers indicate values 1.5xIQR above Q75 and below Q25 
time in labour still warrants the repeated measurement of the foetal heart rate or timing of contractions, it does call into question the notion of watchful waiting which is at the core of basic obstetric care. The use of the partograph, for example, may be perceived as redundant by midwives for a substantial number of women being admitted when birth is imminent. Few studies have recorded time to delivery for normal deliveries, although limited evidence suggests somewhat longer intervals in Benin and Rwanda. ${ }^{11-12}$ Why women arrive at such a late stage is not known, but a better understanding of the barriers to early admission in labour is certainly warranted if quality of care is to be improved.

The 18\% rate of oxytocics administration during the first or second stage of labour and the $24 \%$ episiotomy rate fall within the ranges reported elsewhere. ${ }^{8,24-28}$ However intramuscular oxytocics administration and the very high episiotomy rates among primiparous women are not in line with international recommendations ${ }^{29,30}$ and raise concerns about potential complications.

Uterine revision rates were also worryingly high (32\%), given that manual exploration of the uterus should only be done when there is a suspicion of retained placental fragments. ${ }^{31}$ The placenta was rarely examined, and given the risk of post-partum infection associated with uterine revision and the lack of availability of special gloves, this procedure can be harmful for providers and patients.

This study did not aim at understanding the factors that drive performance, and we cannot comment on the reasons for the very low technical performance in the four health facilities. The difference between facilities was not consistent across indicators, and no facility appeared to stand out as better or worse. Though one might expect second referral level maternities to perform better technically, this was not the case. Essential instruments or tools not being available in the facility (e.g. blood pressure meter, autoclave for sterilization of instruments, albumine sticks or antimicrobial ointment) is certainly part of the problem, but it does not explain all. Providers almost never washed their hands before or after examination or medical procedure, despite the presence of water supplies. Checking uterine retraction and vaginal bleeding before discharge from the delivery ward does not require equipment. Lack of post-partum care for the mother has been described in other studies $8,11,12,15$ and deserves increased attention since a important proportion of maternal deaths occur in the hours following delivery. ${ }^{2}$ Womanprovider interaction was quite limited in our study, as reported in Abidjan and elsewhere. ${ }^{8,9,13,32-34}$ Providing information to the woman about progress of labour, or ensuring continuous support may require organizational changes but no specific equipment. Although continuous support during labour has been proven effective in improving birth outcomes, ${ }^{35}$ such practices are not yet widely applied in Côte d'Ivoire, as in many developing countries. ${ }^{13,14}$ This, together with the high episiotomy rates, the lack of systematic oxytocics administration during the third stage of labour, and the lack of antimicrobial ointment use, illustrates the gap between evidence and practice in obstetric care. ${ }^{16,28,36-38}$

Despite the low technical quality, and the far from optimal personal support given to women during and after labour, most women reported to be satisfied with the care received. Some studies have revealed that pregnant women were fairly uncritical of health care, accepting whatever care they receive as appropriate. ${ }^{39,40}$ Women's satisfaction is an important indicator but its measurement remains a challenge. Overall satisfaction assessed through closed-ended questions represents a limitation and it might be important to examine expressed preferences rather than the absolute magnitude of expressed satisfaction. ${ }^{39,40}$ Qualitative methods may also better capture women's feelings. ${ }^{40}$

The study has some limitations. First, observation bias cannot be excluded. The fact that providers performed so poorly while under 
observation suggests that this bias is small, however. Second, we merely assessed whether an action was performed, not whether it was performed correctly. Where possible, the checklist incorporated elements on how the procedure was done - for example, whether the umbilical cord was cleaned with an antiseptic or other product - but this was not possible for all indicators. Finally, we did not construct average performance indicators by summarising the number of cases fulfilling all criteria. ${ }^{10,17,41}$ The main reason for not computing an average index was that the relative importance of each individual indicator is not known (e.g. is monitoring the foetal heart rate more or less important than measuring uterine height?), and the validity of an average score of aggregate indicators is uncertain. In conclusion, our results show very poor quality of labour, delivery and post-partum care, including the use of practices not based on evidence, even though most deliveries were attended by trained professionals. Since ensuring that all births have a skilled attendant is the main strategy for reducing maternal mortality, ${ }^{2-6}$ efforts must also focus on how quality of care can be improved and sustained. Furthermore, since the proportion of births with a skilled attendant is the key indicator for tracking progress in maternal health, ${ }^{7}$ simple indicators that go beyond the mere measurement of a professional label need to be developed.

\section{Acknowledgements}

We would like to thank the clients and staff at the participating health facilities. This study was funded by MEASURE, United States Agency for International Development (USAID) and by the Belgian Development Cooperation (DGDC). Simon Collin was funded by IMMPACT (Initiative for Maternal Mortality Programme Assessment, see: http://www.abdn.ac.uk/immpact). Carine Ronsmans was funded by IMMPACT, the Department for International Development and the London School of Hygiene and Tropical
Medicine. The funders have no responsibility for the information provided or views expressed in this paper. The views expressed herein are solely those of the authors.

\section{REFERENCES}

1. Word Health Organisation. Fact sheet $\mathrm{N}^{\circ} 245$ : Essential Obstetric care. June 2000. WHO Media centre, Geneva. Access at: http://www.who.int/ mediacentre/factsheets/fs $245 /$ en/.

2. WHO. World Health Report 2005 -make every mother and child count. World Health Organization, Geneva, 2005.

3. WHO, UNFPA, UNICEF, and the World Bank. 1999. Reduction of Maternal Mortality: A Joint WHO/UNFPA/UNICEF/World Bank Statement. Geneva: WHO.

4. World Health Organisation. Making Pregnancy safer: the critical role of the skilled attendant. A joint statement by WHO, ICM and FIGO. WHO, Geneva, 2004.

5. GrahamW, Bell JS, and Bullough HW. Can Skilled Attendance at Delivery Reduce Maternal Mortality in Developing Countries? In: De Brouwere V, Van Lerberghe W, eds. Safe Motherhood Strategies: A Review of the Evidence. Antwerp:ITG Press, 2001. (Studies in Health Services Organisation and Policy; 17: 97-129).

6. Kowalewski M, Jahn A. Health professionals for maternity services: experiences on covering the population with quality maternity care. In: De Brouwere V, Van Lerberghe W, eds. Safe Motherhood Strategies: A Review of the Evidence. Antwerp:ITG Press, 2001. (Studies in Health Services Organisation and Policy; 17: 131-150)

7. United Nations. The Millennium Development Goals Report 2005. United Nations, New York, 2005.

8. Duponchel JL. Projet Equité dans l'accès aux soins en zone urbaine. Rapport Global. Coopération Francaise- Unicef. Mars 2001.

9. Portal Jl, Welffens-Ekra C, Toure-Coulibaly K, Bohoussou KM. La qualité de la prise en charge obstétricale dans le secteur public d'Abidjan. In: Brunet-Jailly, eds. Santé en capitale. Abidjan, 1996.

African Journal of Reproductive Health Vol. 11 No.1 April 2007 
10. Adeyi O, Morrow R. Essential obstetric care: assessment and determinants of quality. Soc Sci Med 1997;45(11):1631-9.

11. Boucar M, Bucagu M, Djibrina S, Edson W, Burkhalter B, Harvey SA, Antonakos C. Safe Motherhood Studies- Results from Rwanda. Quality Assurance Project, May 2004. Access at: http:// www.qaproject.org/pubs / PDFs / Rwanda SO2SafeMotherhood.pdf.

12. Gbangbade S, Harvey SA, Edson W, Burkhalter B, Antonakos C. Safe Motherhood Studies- Results from Rwanda. Quality Assurance Project; November 2003. Access at: http://www.qaproject.org/ pubs/PDFs/BeninMothers.pdf.

13. Maimbolwa MC, Ransjo-Arvidson AB, Ng'andu $\mathrm{N}$, Sikazwe N, Diwan VK. Routine care of women experiencing normal deliveries in Zambian maternity wards: a pilot study. Midwifery 1997;13(3):12531.

14. Miller S, Cordero M, Coleman AL, Figueroa J, BritoAnderson S, Dabagh R, Calderon V, Caceres F, Fernandez AJ, Nunez M. Quality of care in institutionalized deliveries: the paradox of the Dominican Republic. Int J Gynaecol Obstet 2003;82(1):89103.

15. Burkhalter B, Edson W, Harvey S, et al. Quality Assurance project-Operations research results; Quality of obstetric care observed in 14 hospitals in Benin, Ecuador, Jamaica and Rwanda. 2006 USAID.

16. Turan JM, Bulut A, Nalbant H, Ortayli N, Erbaydar T. Challenges for the adoption of evidence-based maternity care in Turkey. Soc Sci Med. 2006 May;62(9):2196-204.

17. Hussein J, Bell J, Nazzar A, Abbey M, Adjei S, Graham W. The skilled attendance index: proposal for a new measure of skilled attendance at delivery. Reprod Health Matters 2004;12(24):160-70.

18. Azandegbe N, Testa J, Makoutode M. [Assessment of partogram utilisation in Benin] [Article in French]. Santé. 2004;14(4):251-5.

19. Jahn A, Dar Iang M, Shah U, Diesfeld HJ. Maternity care in rural Nepal: a health service analysis. Trop Med Int Health 2000;5(9):657-65.

20. Bulatao RA, Ross JA. Rating maternal and neonatal health services in developing countries. Bull World Health Organ. 2002;80(9):721-7.

African Journal of Reproductive Health Vol. 11 No.1 April, 2007
21. Ministère de la Santé Publique (MSP) - République de Côte d'Ivoire. Manuel des directives du paquet minimum d'activités des établissement sanitaires de premier contact, Edition 2000.

22. World Health Organisation. Safe Motherhood Needs Assessment. Maternal and Newborn Health/ Division of Reproductive Health, Family and Reproductive Health, WHO, Geneva, 1996. Access at http://www.who.int/reproductivehealth/MNBH/smna_index.en.html.

23. World Health Organisation. Care in Normal Birth: a practical guide. Maternal and Newborn Health/ Safe Motherhood Unit, Family and Reproductive Health, WHO, Geneva, 1996.

24. Dujardin B, Boutsen M, De Schampheleire I, Kulker R, Manshande JP, Bailey J, Wollast E, Buekens P. Oxytocics in developing countries. Int J Gynaecol Obstet 1995;50(3):243-51.

25. Buekens P. Over-medicalisation of Maternal Care in Developing Countries. In: De Brouwere V, Van Lerberghe W, eds. Safe Motherhood Strategies: A Review of the Evidence. Antwerp:ITG Press, 2001. (Studies in Health Services Organisation and Policy 2001; 17: 195-206).

26. Althabe F, Belizan JM, Bergel E. Episiotomy rates in primiparous women in Latin America: hospital based descriptive study. BMJ 2002;324 (7343): 945-6.

27. Graham ID, Carroli G, Davies C, Medves JM. Episiotomy rates around the world: an update. Birth 2005;32(3):219-23.

28. Carroli G, Belizan J. Episiotomy for vaginal birth (Cochrane Review). In: The Cochrane Library, Issue 2, 2000. Update Software, Oxford, England.

29. World Health Organisation. Managing Complications in Pregnancy and Childbirth. Section 3-Procedures. 2000. Access at: http:/ /www.who.int/reproductive-health/impac/Procedures / Episiotomy_P71_P75.html.

30. World Health Organisation. Managing Complications in Pregnancy and Childbirth. Section 3-Procedures. 2000. Access at:http:// www.who.int/reproductive-health/impac/ Procedures/Induction_P17_P25.html.

31. World Health Organisation. Managing Complications in Pregnancy and Childbirth. Section 
2-Symptoms. 2000. Access at: http:// www.who.int/reproductive-health/impac/ Symptoms Vaginal_bleeding_after_S25_S34. html\#S27\%20 retained $\% 20$ placental $\% 20$ diagnosis.

32. Jaffré Y, de Sardan JPO. Abidjan : Le centre de santé de Sagbé. In: Apad-Karthala, eds. Une médecine inhospitalière: Les difficiles relations entre soignants et soignés dans cinq capitales d'Afrique de l'Ouest. Paris, 2003.

33. Jewkes R, Abrahams N, Mvo Z.Why do nurses abuse patients? Reflections from South African obstetric services. Soc Sci Med. 1998;47(11):178195.

34. MacKeith N, Chinganya OJ, Ahmed Y, Murray SF. Zambian women's experiences of urban maternity care: results from a community survey in Lusaka. AfrJ Reprod Health 2003;7(1):92-102.

35. Hodnett ED, Gates S, Hofmeyr GJ, Sakala C. Continuous support for women during childbirth. In: The Cochrane Library, Issue 1, 2006. Oxford: Update Software.

36. Villar J, Carroli G, Gulmezoglu AM. The gap between evidence and practice in maternal healthcare. Int J Gynaecol Obstet 2001;75 Suppl 1:S47-54.
37. Evidence-led obstetric care. Report of a WHO meeting. Geneva, Switzerland, 28-30 January 2004. access at: http://www.who.int/reproductivehealth/publications/evidence_led_obstetric_care/ text.pdf.

38. Tita AT, Selwyn BJ, Waller DK, Kapadia AS, Dongmo S. Evidence-based reproductive health care in Cameroon: population-based study of awareness, use and barriers. Bull World Health Organ. 2005;83(12):895-903.

39. van Teijlingen ER, Hundley V, Rennie AM, Graham W, Fitzmaurice A. Maternity satisfaction studies and their limitations: "What is, must still be best". Birth. 2003;30(2):75-82.

40. Langer A, Villar J, Romero M, Nigenda G, Piaggio $G$, et al. Are women and providers satisfied with antenatal care? Views on a standard and a simplified, evidence-based model of care in four developing countries. BMC Womens Health. 2002 19;2(1):7.

41. Boller C, Wyss K, Mtasiwa D, Tanner M. Quality and comparison of antenatal care in public and private providers in the United Republic of Tanzania. Bull World Health Organ. 2003;81(2):11622. 